\title{
Vasoconstrictor effect of Africanized honeybee (Apis mellifera $L$.) venom on rat aorta
}

\author{
Paulo César P Sousa ${ }^{1}$, Teresinha S Brito ${ }^{1}$, Daniel S Freire ${ }^{1}$, Rafael M Ximenes ${ }^{1,5}$, Pedro Jorge C Magalhães ${ }^{1}$, \\ Helena SA Monteiro ${ }^{1}$, Renata S Alves ${ }^{2}$, Alice Maria C Martins ${ }^{2}$, Daniela O Toyama ${ }^{3}$ and Marcos H Toyama ${ }^{4 *}$
}

\begin{abstract}
Background: Apis mellifera stings are a problem for public health worldwide, particularly in Latin America due to the aggressiveness of its Africanized honeybees. Massive poisoning by A. mellifera venom (AmV) affects mainly the cardiovascular system, and several works have described its actions on heart muscle. Nevertheless, no work on the pharmacological action mechanisms of the $\mathrm{AmV}$ in isolated aorta has been reported. Thus, the present work aimed to investigate the actions of $A m V$ and its main fractions, phospholipase $A_{2}\left(P L A_{2}\right)$ and melittin, on isolated aorta rings and a probable action mechanism.
\end{abstract}

Results: AmV and the complex PLA 2 + melittin $(0.1-50 \mu \mathrm{g} / \mathrm{mL})$ caused contraction in endothelium-containing aorta rings, but neither isolated PLA 2 nor melittin were able to reproduce the effect. Endothelium removal did not change the maximum vasoconstrictor effect elicited by AmV. Ca ${ }^{2+}$-free medium, as well as treatment with phentolamine $(5 \mu \mathrm{M})$, verapamil $(10 \mu \mathrm{M})$, losartan $(100 \mu \mathrm{M})$, and $\mathrm{U}-73122(10 \mu \mathrm{M}$, a phospholipase $\mathrm{C}$ inhibitor), eliminated the AmV-induced contractile effects.

Conclusions: In conclusion, AmV caused contractile effect in aorta rings probably through the involvement of voltage-operated calcium channels, AT1 and a-adrenergic receptors via the downstream activation of phospholipase C. The protein complex, PLA + melittin, was also able to induce vasoconstriction, whereas the isolated proteins were not.

Keywords: Apis mellifera, Venom, Mellitin, Phospholipase $A_{2}$, Aorta

\section{Background}

Africanized honeybees are a poly-hybrid species found in South America, mainly in Brazil, known for their aggressiveness and involvement in mass attacks [1,2]. The clinical manifestations of bee envenomation are characterized by local and systemic toxicity. Among the systemic manifestations observed after bee stings are cardiovascular changes and renal damage. Despite the significant advances made in understanding the pathogenesis of nephrotoxic and ischemic acute renal failure caused by such envenomation, there have been few changes in terms of mortality [3].

A. mellifera venom $(\mathrm{AmV})$ is a complex mixture of enzymes, peptides and amines. Among the components of the venom are biogenic amines, hyaluronidases,

\footnotetext{
* Correspondence: mhtjpn@yahoo.com

${ }^{4}$ Paulista Coast Experimental Campus, São Paulo State University

(UNESP - Univ Estadual Paulista), São Vicente, São Paulo State, Brazil

Full list of author information is available at the end of the article
}

phospholipases $\mathrm{A}_{2}$ (PLA $)$ and melittin, which is its main constituent, approximately $50 \%$ of the dry weight $[4,5]$. This active 26-amino-acid peptide is released from its precursor, promelittin, during biosynthesis and presents hemolytic activity. It also is the primary allergen found in bee venom [6]. It acts synergistically with phospholipase $\mathrm{A}_{2}\left(\mathrm{PLA}_{2}\right)$ to enhance its toxic actions [7].

Despite published in vivo characterization of the cardiovascular effects of both melittin and PLA 2 , few in vitro experiments that clarify the action mode of these toxins are available in the scientific literature [8]. Some papers report the role of endothelium, lipoxygenase products, and nitric oxide (NO) in the vascular effects of melittin [9-11]. The present study aimed to investigate the vasoconstrictor effect of crude A. mellifera venom (AmV) and its fractions PLA melittin, and the native linked fraction $\left(\mathrm{PLA}_{2}+\right.$ melittin), on isolated aortic rings of rats. 


\section{Methods}

\section{Venom and reagents}

A. mellifera venom was purchased from Bio-Agents Serpentarium (Brazil). All chemicals and solvents were of analytical grade and purchased from certified suppliers (Bayer, Sigma-Aldrich, Labtest Diagnostic and Applied Biosystems).

\section{Animals}

Male Wistar rats (250-300 g) were maintained under standard conditions of temperature and humidity in 12-hour light-dark cycles. The animals had fasted for 24 hours before any experimental procedure, and water was provided ad libitum. All experiments were in accordance with the guidelines for the ethical use of experimental animals published by the Brazilian College on Experimental Animal Care (COBEA), with a project license approved by the Animal Ethics Committee of Federal University of Ceará (protocol number 01/2012).

\section{Purification of PLA 2 and melittin from Apis mellifera venom} The bee venom $\mathrm{PLA}_{2}$ was purified in two chromatographic steps. Briefly, AmV was dissolved $(10 \mathrm{mg} / \mathrm{mL})$ in $\mathrm{NaCl} 0.9 \%$ and kept at $14^{\circ} \mathrm{C}$ under constant stirring. The protein content of the venom was precipitated with pure acetone for 24 hours, centrifuged (4500 $\mathrm{x} g$ ) and lyophilized to obtain the protein fraction, which was used for the fractionation of $\mathrm{PLA}_{2}$. In the first step, the protein fraction was subjected to a molecular exclusion chromatography, using a size exclusion column $(1 \times 60 \mathrm{~cm})$ previously packed with Superdex 75 (GE Healthcare Life Sciences, USA). The column was attached to semi-preparative HPLC and equilibrated with a $0.2 \mathrm{M}$ ammonium bicarbonate buffer ( $\mathrm{pH}$ 7.8). The protein fraction (15 mg) was dissolved in $250 \mu \mathrm{L}$ of the buffer, homogenized, and centrifuged at $4500 \mathrm{x} \mathrm{g}$ for five minutes. The supernatant was filtered through a $0.45 \mu \mathrm{m}$ filter and then injected into the column. Fractionation of the venom was performed at a constant flow rate of $0.3 \mathrm{~mL} /$ minute and monitored at $280 \mathrm{~nm}$. Each fraction was collected for three minutes $(0.9 \mathrm{~mL})$ and tested for phospholipase $\mathrm{A}_{2}$ enzymatic activity.

After confirming the $\mathrm{PLA}_{2}$ enzymatic activity, the fraction was subjected to a new chromatographic step on reversed-phase HPLC using a C18 semi-analytical column, which was equilibrated with buffer A (0.1\% TFA), to isolate the $\mathrm{PLA}_{2}$ and melittin. Samples of the fraction with PLA activity ( $3 \mathrm{mg}$ ) were dissolved in $250 \mathrm{~mL}$ of buffer A, clarified and injected into the chromatographic column. The elution was performed with a continuous linear gradient of buffer B (66\% acetonitrile in $0.1 \%$ TFA) and the monitoring was done at $280 \mathrm{~nm}$. The samples from the first chromatographic step were analyzed by SDS-PAGE, using a running gel of $12 \%$ acrylamide and a stacking gel of $5 \%$ acrylamide, with bisacrylamide $(0.32 \%)$ as cross-linker.

\section{Mass spectrometry}

The molecular masses of the $\mathrm{PLA}_{2}$ and melittin were determined by matrix-assisted laser desorption/ionization time-of-flight (MALDI-TOF) mass spectrometry using a Voyager-DE PROMALDI-TOF mass spectrometer (Applied Biosystems ${ }^{\oplus}$, Life Technologies ${ }^{\mathrm{TM}}$, USA). One microliter of the sample dissolved in $0.1 \%$ TFA was mixed with $2 \mu \mathrm{L}$ of the matrix ( $\alpha$-cyano-4-hydroxycinnamic acid). The matrix was prepared with $30 \%$ acetonitrile and $0.1 \%$ TFA (v/v). Ion masses were determined at an acceleration voltage of $25 \mathrm{kV}$, the laser operating at $2890 \mu \mathrm{J} / \mathrm{com} 2$, with a 300 ns delay and a linear analysis mode.

\section{Aortic ring assay}

The rats were sacrificed by stunning followed by cervical dislocation. The thoracic aorta were removed and immersed in a perfusion medium (Krebs-Henseleit solution) at room temperature. After removing adhering fat and connective tissue, each aorta was cut transversally into cylindrical ring-like segments (1 x $5 \mathrm{~mm})$ attached to steel wire triangular pieces ( $0.3 \mathrm{~mm}$ diameter), which were suspended in a $5 \mathrm{~mL}$ organ bath containing Krebs-Henseleit solution ( $\mathrm{pH}$ 7.4) with the following composition (mM): $\mathrm{NaCl}$ 118.0, $\mathrm{KCl} 4.7, \mathrm{MgSO} 4$ 1.2, $\mathrm{CaCl} 2$ 2.5, $\mathrm{KH} 2 \mathrm{PO} 4$ 1.2, NaHCO3 25.0 and glucose 11.1 , continuously aerated at $37^{\circ} \mathrm{C}$ with $95 \% \mathrm{O}_{2}$ and $5 \% \mathrm{CO}_{2}$.

In some aortic tissues, endothelium was removed immediately after dissection by gentle rubbing of the aortic lumen with a stainless steel wire. Endothelium-containing or denuded strips were stretched with a passive tension of $1 \mathrm{~g}$ while the tension was recorded using an isometric force transducer (ML870B60/C-V, AD Instruments, Australia) connected to a digital data acquisition system (PowerLab ${ }^{\text {тM }}$ $8 / 30, \mathrm{AD}$ Instruments). After an equilibration period of at least 60 minutes, control contractions were induced by adding a submaximal concentration $(60 \mathrm{mM})$ of potassium chloride $(\mathrm{KCl})$ to the bath. When two successive control contractions showed similar amplitudes, preparations were considered equilibrated. Contraction data were expressed as percentages of the potassium-induced contraction. Endothelium-containing or -denuded preparations were contracted at the beginning of the experiment with potassium $(30 \mathrm{mM})$ and after establishment of a contractile plateau, they were challenged with $1 \mu \mathrm{M}$ of acetylcholine. The lack of acetylcholine-induced vasorelaxant effects was interpreted as evidence that the preparation was effectively denuded of endothelium [3].

Effects of the $A$. mellifera venom (AmV) in isolated rat aorta Concentration-effect curves of $\mathrm{AmV}$ were obtained by exposing a preparation in basal tonus to cumulatively increasing concentrations of $\mathrm{AmV}(0.1$ to $50 \mu \mathrm{g} / \mathrm{mL})$ added to the bath and maintaining it at a given concentration for five minutes. The vasoconstrictor effects of AmV were 
determined in preparations without functional endothelium. In order to investigate the vasoconstrictor effect of AmV, concentration-effect curves were constructed by exposing the preparations to cumulatively increasing concentrations of $\mathrm{AmV}$ in basal tonus in preparations maintained in a $\mathrm{Ca}^{2+}$-containing medium, in a $\mathrm{Ca}^{2+}$-free medium (containing $2 \times 10^{-5} \mathrm{M}$ EGTA), and in the presence of verapamil $(10 \mu \mathrm{M})$, a well-known L-type voltageoperated $\mathrm{Ca}^{2+}$ channel (VOCC) blocker, phentolamine $(5 \mu \mathrm{M})$, an $\alpha$-adrenergic blocker, losartan $(100 \mu \mathrm{M})$, an angiotensin II AT1 receptor antagonist, and U73122 $(10 \mu \mathrm{M})$, a phospholipase $\mathrm{C}$ inhibitor.

\section{Effects of the AmV fractions, $\mathrm{PLA}_{2}$ and melittin, on isolated rat aorta}

In order to investigate whether the fractions $\mathrm{PLA}_{2}$ and melittin were involved in the vasoconstrictor effects of the AmV, concentration-effect curves $(0.1$ to $50 \mu \mathrm{g} / \mathrm{mL})$ were constructed by exposing the preparations to cumulatively increasing concentrations of the fractions, $\mathrm{PLA}_{2}$, melittin and the complex $\mathrm{PLA}_{2}+$ melittin $(1: 1, \mathrm{w}: \mathrm{w})$.

\section{Statistical analysis}

Data were reported as means \pm SEM. The means were evaluated by ANOVA, followed by the Holm-Sidak post hoc test. Emax values were compared using the unpaired Student's $t$ test. The acceptance level for statistically significant differences was set at 5\% ( $<<0.05)$.

\section{Results}

\section{Fractionation of $A$. mellifera crude venom}

A. mellifera crude venom fractionation through size exclusion chromatography showed the presence of nine fractions, designated sequentially I to IX, as shown in Figure 1A. Only the fraction VI showed phospholipasic $\mathrm{A}_{2}$ enzymatic activity. The SDS-PAGE analysis of fraction VI revealed the presence of two major fractions as well as a minor electrophoretic band (results not shown). This fraction was subjected to a reverse phase HPLC. The chromatographic profile of the purification of the fraction VI showed five peaks, which were denominated sequentially VI-1 to VI-5, where the most important fractions in terms of chromatogram area were VI-3 and VI-4 (Figure 1B). The analysis on SDS-PAGE of these fractions showed that VI-3 had a molecular mass of approximately $15 \mathrm{kDa}$ (Figure 1C). Fraction VI-4 was not detected using a $10 \%$ acrylamide gel. This result suggested that fraction VI-4 must have a molecular mass lower than $10 \mathrm{kDa}$. PLA $\mathrm{P}_{2}$ enzymatic activity was found only in fraction VI-3, whereas fraction VI-4 reduced the $\mathrm{PLA}_{2}$ of fraction VI-3. Finally, a MALDI-TOF analysis, to confirm the molecular homogeneity of PLA $\mathrm{P}_{2}$ and melittin, revealed respective molecular masses of $15,343.31 \mathrm{Da}$ and 3,101.03 $\mathrm{Da}$ for the $\mathrm{PLA}_{2}$ and melittin.
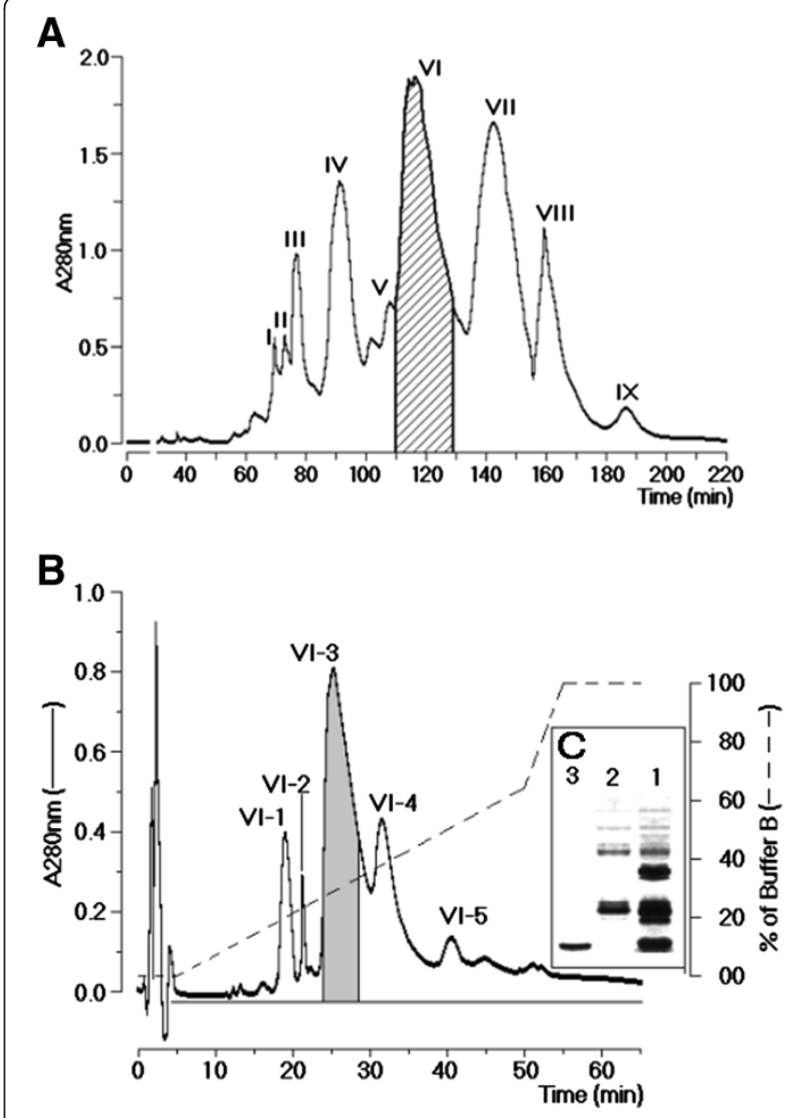

Figure 1 Fractionation of AmV. (A) Chromatography of whole protein extract from honeybee venom using a molecular exclusion column packed with Superdex ${ }^{\oplus 5}$. The chromatographic run was carried out at a flow rate of 0.6 $\mathrm{mL} / \mathrm{h}$ and monitored at $280 \mathrm{~nm}$. (B) Reverse phase HPLC run yielded five main fractions designated from VI-1 to VI-5. Fraction $\mathrm{VI}-3$ was confirmed as $\mathrm{PLA} 2$ by specific phospholipase $\mathrm{A}_{2}$ assay and fraction $\mathrm{VI}-4$ as melittin after MALDI-TOFF analysis. (C) SDS-PAGE analysis of the purified proteins.

Effect of $A$. mellifera venom and its fractions in isolated aorta In endothelium-containing aorta preparations, AmV (0.1-50 $\mathrm{\mu g} / \mathrm{mL})$ induced contractile responses in a concentration-dependent manner. The magnitude of the contraction induced by $50 \mu \mathrm{g} / \mathrm{mL}$ of $\mathrm{AmV}$ corresponded to $92.6 \pm 5.5 \%$ ( $n=5$ rings) of a reference contraction induced by $60 \mathrm{mM} \mathrm{K}$. In the same preparation, the isolated $\mathrm{PLA}_{2}$ or melittin $(0.1-50 \mu \mathrm{g} / \mathrm{mL})$ did not induce significant contractile responses. However, the complex $\mathrm{PLA}_{2}+$ melittin $(0.1-50 \mu \mathrm{g} / \mathrm{mL})$ induced a vasoconstrictor effect in a concentration-dependent manner, $(n=4$ rings; $\mathrm{p}<0.05$; Figure 2A). The magnitude of the contractile effect at $50 \mu \mathrm{g} / \mathrm{mL}$ was $66.1 \pm 11.9 \%$ of the contraction induced by $\mathrm{K}^{+}(60 \mathrm{mM})$. Endothelium removal did not change the maximum vasoconstrictor effect elicited by AmV (Figure 2B). 

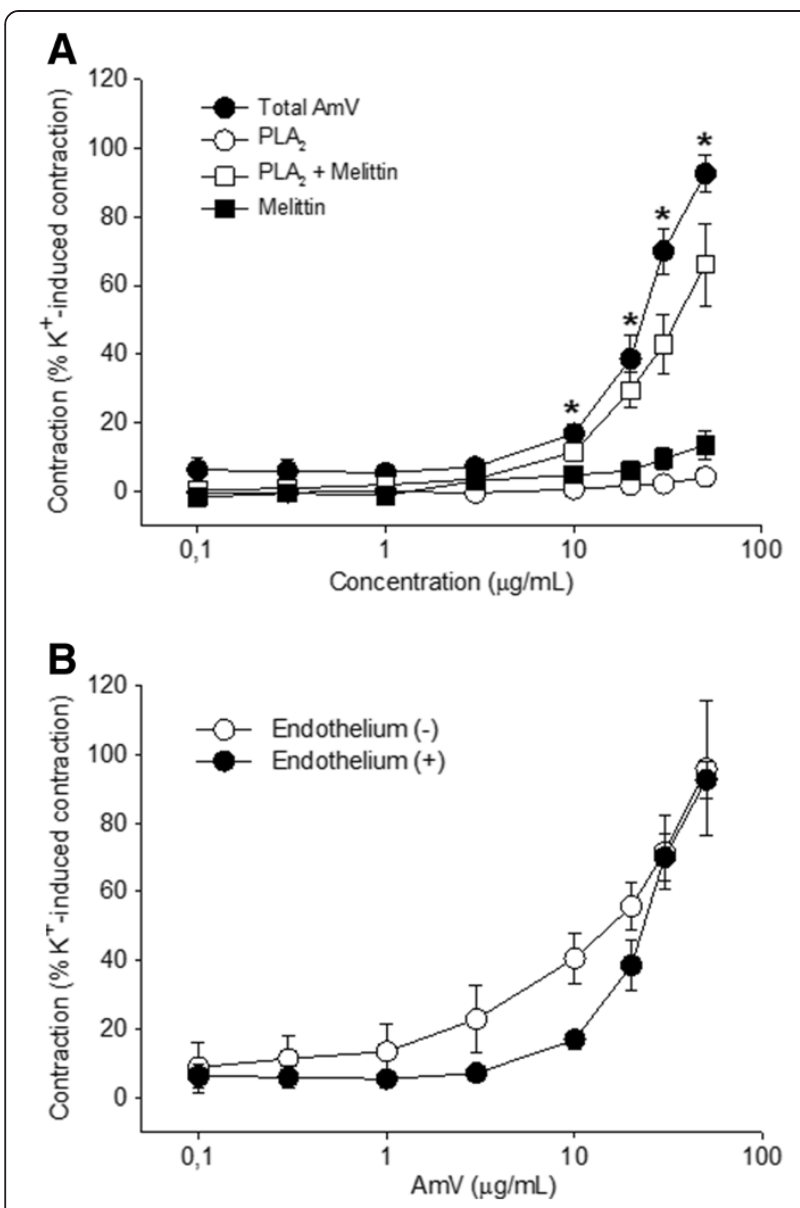

Figure $\mathbf{2}$ Characterization of the vasoconstrictor effect of AmV. (A) Vasoconstrictor effect of $\mathrm{AmV}(0.1-50 \mu \mathrm{g} / \mathrm{mL})(\bullet, \mathrm{n}=5)$ and the fractions: melittin $(\mathbf{\square}, \mathrm{n}=5) ; \mathrm{PLA}_{2}(\mathrm{O}, \mathrm{n}=5)$; and the complex $P L A_{2}+$ melittin $(\square, n=5)$. (B) Effect of endothelium removal on AmV vasoconstrictor effect. The concentration response curve of AmV (0.1-50 $\mu \mathrm{g} / \mathrm{mL})$ on basal tone in endothelium-containing aorta preparations $(\bullet, n=5)$, and in endothelium-denuded aorta preparations $(\mathrm{O}, \mathrm{n}=4)$. Vasoconstrictor effects are expressed as a percentage of the contractile response to $\mathrm{K}^{+}(60 \mathrm{mM})$. Data are expressed as mean \pm SEM and analyzed by ANOVA followed by the Holm-Sidak post hoc test.

\section{Elucidation of the mode of action of $A$. mellifera venom in} isolated aorta

In aortic rings maintained in the $\mathrm{Ca}^{2+}$-free medium, the contractile effects induced by AmV were abolished and the magnitude of the maximal contraction was $3.7 \pm 3.0 \%$ of the $\mathrm{K}^{+}(60 \mathrm{mM})$ value $(\mathrm{n}=5 ; \mathrm{p}<0.05$; Figure $3 \mathrm{~A})$, a value significantly lower than that observed in $\mathrm{Ca}^{2+}$-containing medium. Pretreatment of aortic rings with phentolamine $(5 \mu \mathrm{M})$ also significantly reduced AmV -induced contraction $(50 \mu \mathrm{g} / \mathrm{mL})$ to $26.8 \pm 5.6 \%$ of the $\mathrm{K}^{+}(60 \mathrm{mM})$ value ( $\mathrm{n}=5$ rings; $\mathrm{p}<0.05$; Figure $\left.3 \mathrm{~B}\right)$. In order to evaluate the effect of a voltage-gated calcium channel blocker on AmV-induced contraction, preparations were treated with verapamil $(10 \mu \mathrm{M})$ after which the
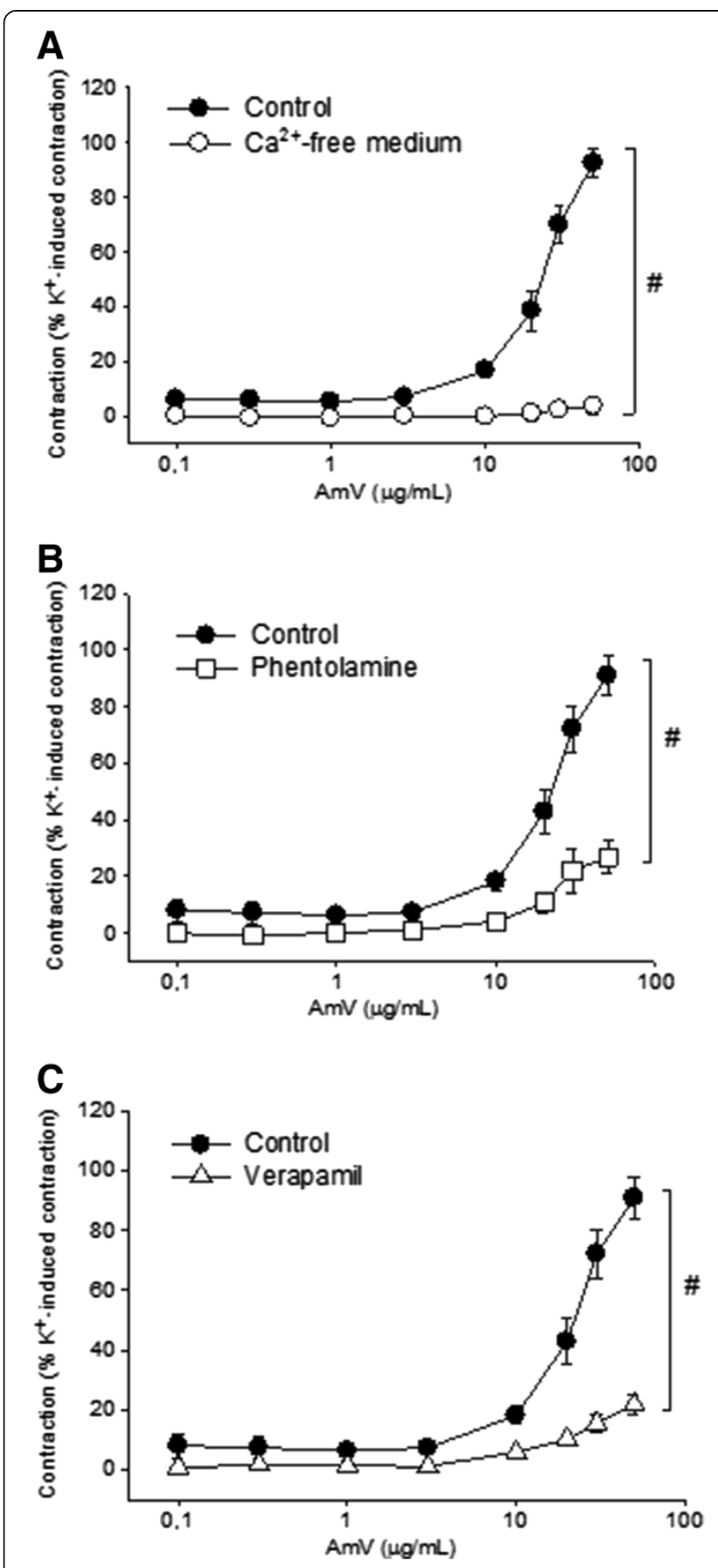

Figure 3 Study on the probable action mode of AmV.

Vasoconstrictor effects of $\mathrm{AmV}$ : (A) $\mathrm{Ca}^{2+}$-free medium $(\mathrm{O}, \mathrm{n}=5)$;

(B) pretreatment with phentolamine $(5 \mu \mathrm{M} ; \square, \mathrm{n}=5)$; (C)

pretreatment with verapamil $(10 \mu \mathrm{M} ; \Delta, \mathrm{n}=5)$. Vasoconstrictor effects are expressed as a percentage of the contractile response to $\mathrm{K}^{+}(60 \mathrm{mM})$. Data are expressed as mean \pm SEM and analyzed by ANOVA followed by the Holm-Sidak posttest.

contractions elicited by $\mathrm{AmV}(50 \mu \mathrm{g} / \mathrm{mL})$ significantly diminished to $21.7 \pm 3.3 \%$ of the $\mathrm{K}^{+}(60 \mathrm{mM})$ value $(\mathrm{n}=4$ rings; $\mathrm{p}<0.05$; Figure $3 \mathrm{C}$ ).

Aiming to verify whether angiotensin was involved in the contractions induced by AmV, an AT1 receptor antagonist 
was employed. The preparations were treated with losartan $(100 \mu \mathrm{M})$, and the contractions elicited by $\mathrm{AmV}$ were decreased to $27.3 \pm 2.4 \%$ of the $\mathrm{K}^{+}(60 \mathrm{mM})$ value $(\mathrm{n}=4$ rings; $\mathrm{p}<0.05$; Figure 4A). Moreover, pretreatment of aortic rings with $\mathrm{U}-73122(10 \mu \mathrm{M})$, a phospholipase $\mathrm{C}$ inhibitor, significantly reduced AmV-induced contraction $(50 \mu \mathrm{g} / \mathrm{mL})$ to $38.4 \pm 5.6 \%$ of the $\mathrm{K}^{+}(60 \mathrm{mM})$ value, respectively ( $\mathrm{n}=5$ rings; $\mathrm{p}<0.05$; Figure $4 \mathrm{~B})$.

\section{Discussion}

The present work describes the isolation of three fractions from the venom of $A$. mellifera, a mixed fraction of $\mathrm{PLA}_{2}$ and melittin, and both in pure protein form $\mathrm{PLA}_{2}$ and melittin. These proteins together represent approximately $60 \%$ of the venom dry weight $[12,13]$. A vasoconstrictor effect of $\mathrm{AmV}$ and the complex $\mathrm{PLA}_{2}+$ melittin was confirmed. However, the isolated $\mathrm{PLA}_{2}$ and melittin had no contractile effect on the aortic rings. Some authors reported that melittin facilitates the interaction of $\mathrm{PLA}_{2}$
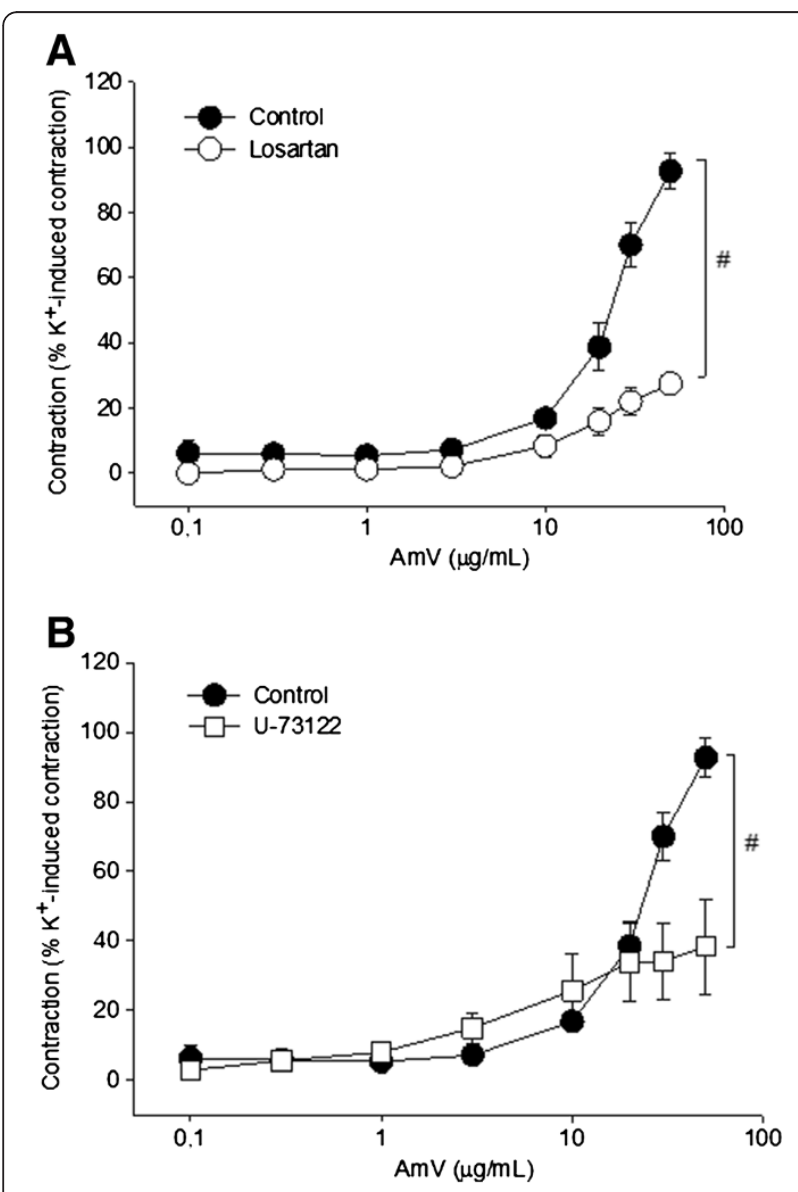

Figure 4 Study on the probable action mode of AmV. Vasoconstrictor effects of AmV: (A) pretreatment with losartan $(100 \mu \mathrm{M} ; \mathrm{O}, \mathrm{n}=5)$; (B) pretreatment with $\mathrm{U}-73122(10 \mu \mathrm{M} ; \mathrm{\square}, \mathrm{n}=5)$. Vasoconstrictor effects are expressed as a percentage of the contractile response to $\mathrm{K}^{+}(60 \mathrm{mM})$. Data are expressed as mean \pm SEM and analyzed by ANOVA followed by the Holm-Sidak posttest. with the cell membrane, exposing the membrane to the catalytic site of the enzyme due to its amphipathic characteristics [3]. In order to investigate the action mode of $A$. mellifera-induced vasoconstriction, the involvements of extracellular $\mathrm{Ca}^{2+}$, voltage-gated calcium channels, $\alpha_{2}$-adrenergic receptors, AT1 receptors and phospholipase $\mathrm{C}$ were assayed.

In $\mathrm{Ca}^{2+}$-free medium, an inhibition of the contractile response of $\mathrm{AmV}$ was observed. Likewise, employing verapamil, a calcium channel blocker, produced an absence of the AmV-induced contractile response. We suggested that the vasoconstrictor properties are dependent on a trans-membrane $\mathrm{Ca}^{2+}$ influx. Thus, the opening of voltageoperated calcium channels is involved in the mechanism proposed for the contractile effect of AmV.

In most cases, a smooth muscle contraction involves a combination of input and $\mathrm{Ca}^{2+}$ release. The various types of smooth muscle may differ markedly in this regard: in the relative contribution of the two sources of $\mathrm{Ca}^{2+}$ for contraction (intracellular and extracellular) and in ion channels through which extracellular $\mathrm{Ca}^{2+}$ can have access to the interior of the cell [14]. According to Jackson [15], the contraction of vascular smooth muscle occurs primarily by the influx of $\mathrm{Ca}^{2+}$ into the muscle cell. If the extracellular concentration of $\mathrm{Ca}^{2+}$ is reduced, the contraction is almost eliminated.

Adrenergic receptors consist of typical G-protein-coupled receptors. Each of these receptor classes, $\alpha_{1}$ - and $\alpha_{2}$ adrenergic receptors, is associated with a specific system of secondary messengers. The $\alpha_{1}$-adrenergic receptors are coupled to phospholipase $\mathrm{C}$ and produce their effects mainly through the release of intracellular $\mathrm{Ca}^{2+}$ stores, mediating vasoconstriction [16].

In an attempt to elucidate the pathway involved in the contraction of the aorta by AmV, an $\alpha$-adrenergic receptor blocker (phentolamine), an AT1 receptor antagonist (losartan), and a phospholipase C inhibitor (U-73122) were used. A significant reduction in the contractile effect of AmV on the aortic rings was observed, suggesting the involvement of these receptors in tissue contraction via phospholipase $C$.

This hypothesis is corroborated by Vinhote et al. [17], who reported such contraction in aortic rings, induced by Polybia paulista wasp venom, showing that the effect was dependent on voltage-operated calcium channels, and that $\alpha$-adrenergic receptors were involved.

\section{Conclusions}

In conclusion, Apis mellifera venom causes a contractile effect on aorta rings probably through the involvement of voltage-operated calcium channels, AT1 and $\alpha$-adrenergic receptors via the downstream activation of phospholipase C. In contrast to the isolated proteins, the protein complex $\mathrm{PLA}_{2}+$ melittin was also able to induce vasoconstriction. 


\section{Ethics committee approval}

The present study was approved by the Animal Ethics Committee of Federal University of Ceará (protocol number 01/2012). Moreover, all experiments were in accordance with the guidelines for the ethical use of experimental animals published by the Brazilian College on Experimental Animal Care (COBEA).

\section{Competing interests}

The authors declare that there are no competing interests.

\section{Authors' contributions}

PCPS, TSB, DSF, RSA, DOT and performed the biochemical and pharmacological experiments. PJCM, HSAM, AMCM, MHT designed the study and discussed the results. RMX, AMCM and MHT drafted the manuscript. All authors read and approved the manuscript.

\section{Acknowledgments}

The authors would like to thank the National Council for Scientific and Technological Development (CNPq), the Coordination for the Improvement of Higher Education Personnel (CAPES) and the Cearense Foundation for Research Support (FUNCAP) for their financial support and Sidney Ann Pratt for language revision.

\section{Author details}

${ }^{1}$ Department of Physiology and Pharmacology, Federal University of Ceará, Fortaleza, Ceará State, Brazil. 'Department of Clinical and Toxicological Analyses, Federal University of Ceará, Fortaleza, Ceará State, Brazil. ${ }^{3}$ Center of Biological and Health Sciences, Mackenzie Presbyterian University, São Paulo, São Paulo State, Brazil. ${ }^{4}$ Paulista Coast Experimental Campus, São Paulo State University (UNESP - Univ Estadual Paulista), São Vicente, São Paulo State, Brazil. ${ }^{5}$ Department of Antibiotics, Federal University of Pernambuco, Recife, Pernambuco State, Brazil.

Received: 6 April 2013 Accepted: 3 September 2013

Published: 25 September 2013

\section{References}

1. Kerr WE: The history of introduction of African bees to Brazil. South African Bee J 1967, 39(2):3-5.

2. Brizola-Bonacina AK, Alves W, de Moraes M: Relation between the size of the acid gland and the quantity of venom produced in africanized bee, Apis mellifera L. (Hymenoptera: Apidae), in the region of Dourados, MS, Brazil. Neotrop Entomol 2006, 35(2):210-214.

3. Furchgott RF, Zawadzki JV: The obligatory role of endothelial cells in the relaxation of arterial smooth muscle by acetylcholine. Nature 1980, 288(5789):373-376.

4. De Melo MH, da Silva EA, Natal D: Africanized bees in a metropolitan area of Brazil: shelters and climatic influences. Rev Saúde Púb/ 2003, 37(2):237-241.

5. Ferreira Junior RS, Sciani JM, Marques-Porto R, Junior AL, Orsi R de O, Barraviera B, Pimenta DC: Africanized honey bee (Apis mellifera) venom profiling: Seasonal variation of melittin and phospholipase $A(2)$ levels. Toxicon 2010, 56(3):355-362.

6. de Graaf DC, Aerts M, Danneels E, Devreese B: Bee, wasp and ant venomics pave the way for a component-resolved diagnosis of sting allergy. J Proteomics 2009, 72(2):145-154.

7. Kreil G, Bachmayer $\mathrm{H}$ : Biosynthesis of melittin, a toxic peptide from bee venom. Detection of a possible precursor. Eur J Biochem 1971, 20(3):344-350.

8. Schumacher MJ, Egen NB: Significance of Africanized bees for public health. A review. Arch Intern Med 1995, 155(19):2038-2043.

9. Cerne K, Kristan KC, Budihna MV, Stanovnik L: Mechanisms of changes in coronary arterial tone induced by bee venom toxins. Toxicon 2010 56(3):305-312.

10. Forstermann U, Neufang B: Endothelium-dependent vasodilation by melittin: are lipoxygenase products involved? Am J Physiol 1985, 249(1 Pt 2):H14-19.

11. Rapoport RM, Ashraf M, Murad F: Effects of melittin on endothelium-dependent relaxation and cyclic GMP levels in rat aorta. Circ Res 1989, 64(3):463-473.

12. Chaud-Netto J, da Silva GP, Brochetto-Braga MR, Palma MS, Rodrigues A, Carmona EC: Influence of the collection methodology on the Apis mellifera venom composition: peptide analysis. Sociobiology 2006, 47(3):761-770.

13. Schmidt JO: Toxinology of venoms from the honeybee genus Apis. Toxicon 1995, 33(7):917-927.

14. Yonamine CM, Costa H, Silva JAA, Muramoto E, Rogero JR, Troncone LRP, Camillo MAP: Biodistribution studies of bee venom and spider toxin using radiotracers. J Venom Anim Toxins ind Trop Dis 2005, 11(1):39-50.

15. Jackson WF: Ion channels and vascular tone. Hypertension 2000, 35(1 Pt 2):173-178.

16. Webb RC: Smooth muscle contraction and relaxation. Adv Physiol Educ 2003, 27(4):201-206.

17. Vinhote JFC, Torres AFC, Dantas RT, Praciano TP, Menezes RRPPB, Sousa DF, Brito TS, Lima FJB, Toyama MH, Magalhães PJ, Monteiro HSA, Martins-Nunes AMC: Renal and calcium-dependent vascular effects of Polybia paulista wasp venom. J Venom Anim Toxins incl Trop Dis 2011, 17(2):199-208.

doi:10.1186/1678-9199-19-24

Cite this article as: Sousa et al:: Vasoconstrictor effect of Africanized honeybee (Apis mellifera L.) venom on rat aorta. Journal of Venomous Animals and Toxins including Tropical Diseases 2013 19:24.

\section{Submit your next manuscript to BioMed Central and take full advantage of:}

- Convenient online submission

- Thorough peer review

- No space constraints or color figure charges

- Immediate publication on acceptance

- Inclusion in PubMed, CAS, Scopus and Google Scholar

- Research which is freely available for redistribution 